\title{
BACTERIAL ENDOCARDITIS AFTER A TAUSSIG-BLALOCK OPERATION IN A CASE OF UNUSUAL PATHOLOGY
}

\author{
BY \\ H. EVERLEY JONES and E. G. DOLTON
From the Royal Hospital, Wolverhampton
}

(RECEIVED FOR PUBLICATION SEPTEMBER 19, 1951)

The introduction of the Taussig-Blalock operation to improve the pulmonary circulation in certain cases of cyanotic congenital heart disease has meant that successfully treated subjects, though much improved in their functional ability, have been given yet another cardiovascular abnormality. This extra lesion is an artificial ductus arteriosus, a condition which, when solitary and uncomplicated, is regarded as an indication for operative closure. One of the reasons for such closure is the risk to the patient of bacterial endocarditis developing. As quite a large series of successfully completed TaussigBlalock operations have now been recorded it is rather surprising to find only one case (Hurst, Gleason and Schemm, 1949) reported in which bacterial endocarditis followed the operation, though this may in part be due to the fact that the commonest age incidence of this disease lies between 20 and 40 years.

The child to be described suffered such a complication and, in addition, had an unusual form of congenital heart disease.

\section{Case Report}

M.P. was first seen in December, 1947, when 5 years old. She was the seventh of eight living children, all the others being healthy. Two siblings had died of irrelevant causes. She was born at term, the product of a normal pregnancy and labour (though her mother had had some teeth extracted when 4 months pregnant) and weighed $8 \frac{1}{2} \mathrm{lb}$. at birth. She was bottle-fed from the neonatal period and had been subject to cough since she was 3 weeks old. Cyanosis was first noticed by the mother at 3 months. The baby had had a number of severe cyanotic attacks with dyspnoea and had been admitted to hospital in several of these attacks. In one of them, the last to occur, when aged 3 years, she had become unconscious and lost the use of the left arm for three weeks, presumably due to cerebral thrombosis. Her development was slow and she did not sit up alone until she was 2 years old, while she did not talk until
4 years of age and could not walk when examined. Solid food was taken from 9 months of age and her appetite was good. She recognized pictures but could only scribble illegibly and was regarded as mentally defective. There had been no convulsions. She was dyspnoeic on the slightest exertion.

On examination she was seen to be very small and weighed $28 \mathrm{lb}$. She was markedly cyanosed and had pronounced clubbing of fingers and toes. The limbs were thin and hypotonic and she was unable to stand. The chest wall bulged to the right of the sternum and the apex beat was not located. The heart sounds were loudest to the right of the sternum. There was a rough systolic murmur maximal in the third interspace close to the sternum and equally heard on both sides of this structure. The second sound was single. The blood pressure was 105/75. The lungs were clear and there was no sign of congestive failure. She had left otitis media.

Investigations showed $\mathrm{Hb} .120^{\circ}{ }_{\mathrm{o}}$, and red cells $6,900,000$ per c.mm.

Cardioscopy showed a boot-shaped heart, slight cardiac enlargement, apparently involving the right ventricle, or absent pulmonary cone, and a right-sided aortic arch. The lung fields were translucent.

An E.C.G. showed left axis deviation. There were prominent $P$ waves in leads $I$ and $I I$, an inverted $T_{1}$ and slight elevation of $\mathrm{ST}_{2}$ and $\mathrm{ST}_{3}$ (Fig. 1).

An angiocardiogram showed that the aorta filled simultaneously with a narrowed pulmonary artery, and confirmed the right aortic arch. The ventricular septum was not defined.

The cardiographic findings cast serious doubt on the diagnosis of the tetralogy of Fallot which was entertained on the clinical and radiological findings. Brown states that such a finding in the absence of bundle branch block excludes a pulmonary stenosis, although Gasul, Richmond and Krakower (1949) recorded a case of the tetralogy with a patent foramen ovale ("pentalogy ') with left axis deviation, and two cases of the tetralogy with associated patent ductus arteriosus showed left axis deviation with unipolar leads (Sokolow and Edgar, 1950). The usual cause of left axis deviation is tricuspid atresia, but a persistent truncus arteriosus or a common 
ventricle with hypoplastic right ventricle is sometimes found (Brown, 1950).

Under observation the child was seen to be severely incapacitated though she was taught to walk a little with support and slight exertion produced dyspnoea. She

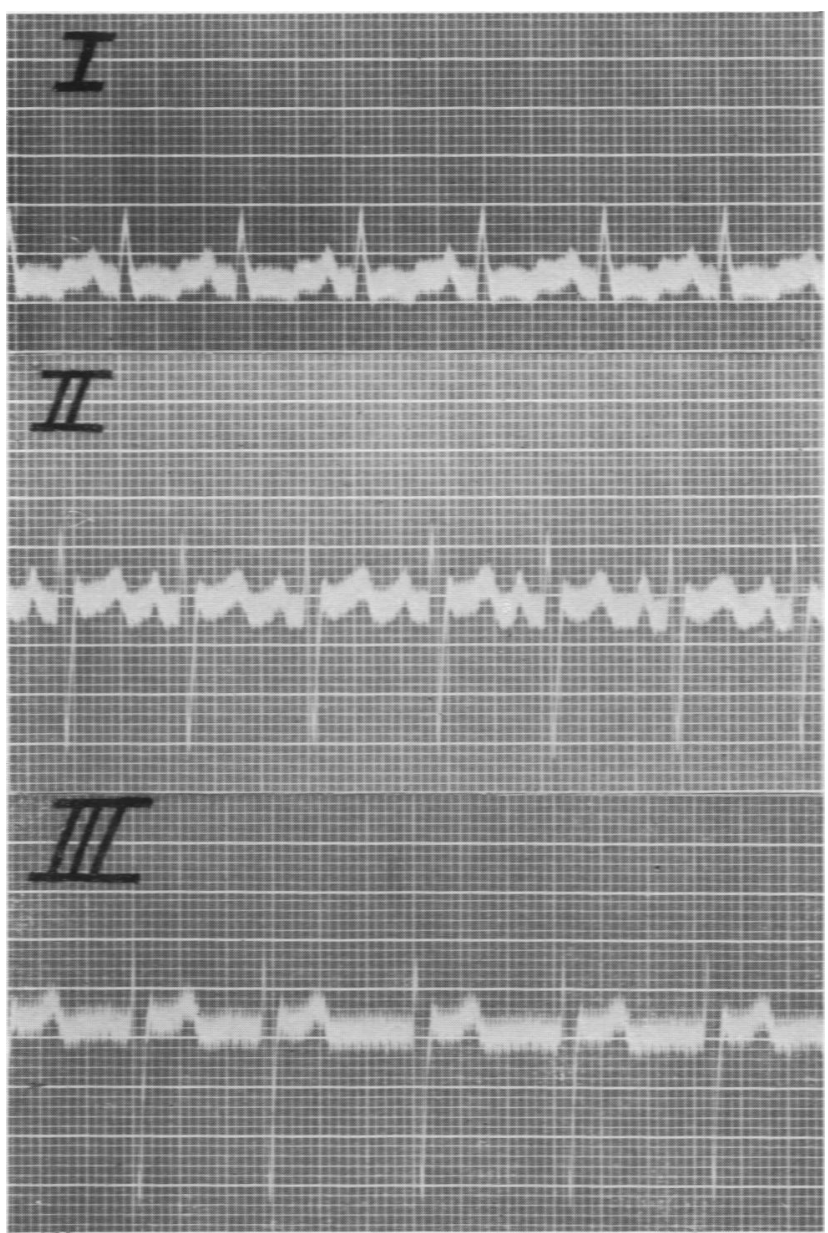

FIG. 1.-E.C.G. showing left axis deviation.

showed herself capable of learning and her speech and intelligence improved. In view of the miserable existence she was leading operation was advised, as the translucent lung fields led to the hope that a pulmonosystemic anastomosis would increase arterial oxygenation.

Operation was performed on August 11, 1948, under a general anaesthetic given by Dr. J. F. Rickards. The left third intercostal space was opened anteriorly with division of the second costal cartilage. A pulmonary artery of adequate size was present, and an end-to-side subclavian to pulmonary artery anastomosis was made using Blalock's early technique. On releasing the clamps, no leak occurred, the anastomosis appeared to function adequately, and the chest was then closed without drainage. The child's condition throughout the operation and her subsequent recovery were entirely satisfactory.

Progress after operation was slow and rather difficult to assess owing to her inability to walk alone. Marked valgus deformity of the feet necessitated a period of immobilization after which she needed irons, and 18 months had passed before she was able to dispense with this aid. By then she was able to walk well and even turn somersaults. She could accompany her mother shopping, walking slowly, and climb stairs. There was a striking improvement in her mentality and she became much more alert and showed a fair aptitude to learn. The cyanosis decreased slowly, but was always present to a slight degree. Six weeks after operation haemoglobin was $85^{\circ}$ o and red cells $4,700,000$. The heart became larger and a machinery murmur became audible in addition to the pre-existing systolic bruit.

She continued satisfactorily until December, 1950, when she contracted infective hepatitis. After two weeks she seemed quite well again and remained so until mid-January, 1951, when she had a febrile respiratory infection. From then until the time of admission to hospital on February 12 she complained of lassitude and lost weight. On admission, at the age of 8 , she was very thin (weight $32 \mathrm{lb}$.), and showed a mixture of pallor and cyanosis. The temperature was normal, pulse 120 , respirations 30 . The clubbing of fingers and toes had changed little from when first seen. Dental caries and marked gingivitis were present, and a few purpuric spots were noted on the right side of the chest. The operation scar was sound. The heart was enlarged, the apex beat being $\frac{1}{2}$ in. outside the mid-clavicular line in the fifth interspace. A harsh systolic murmur, maximal at the second and third interspaces, and a continuous murmur at the first and second right interspaces were heard. Blood pressure was 105/70. There were diminished breath sounds at the right base and basal râles in both lungs. The spleen was enlarged two fingerbreadths below the costal margin.

No other abnormalities were noted.

Special investigations showed the following: Hb. $65^{\circ}$ : red cells $3,800,000$ : leucocytes 11,800 (polvmorphs $61^{\circ}{ }_{0}$, lymphocytes $35^{\circ}{ }_{0}$, monocytes $4^{\circ}{ }_{o}$ ). The E.S.R. was $15 \mathrm{~mm}$. in the first hour. The bleeding time was $4 \frac{1}{2}$ minutes, and the coagulation time 7 minutes. Platelets were 50,000 per c.mm.

The urine on repeated examination showed a trace of albumin but no red cells.

A blood culture showed a growth of non-haemolytic streptococci twice in four days.

Serum bilirubin was $7 \mathrm{mg}$. per litre.

The Van den Bergh test gave a faint positive indirect reaction.

Serum protein was 3.9 g. ${ }^{\circ}$, albumin 1.5 g. ${ }^{\circ}$, globulin $2 \cdot 4 \mathrm{~g}^{\circ}{ }_{0}$. 


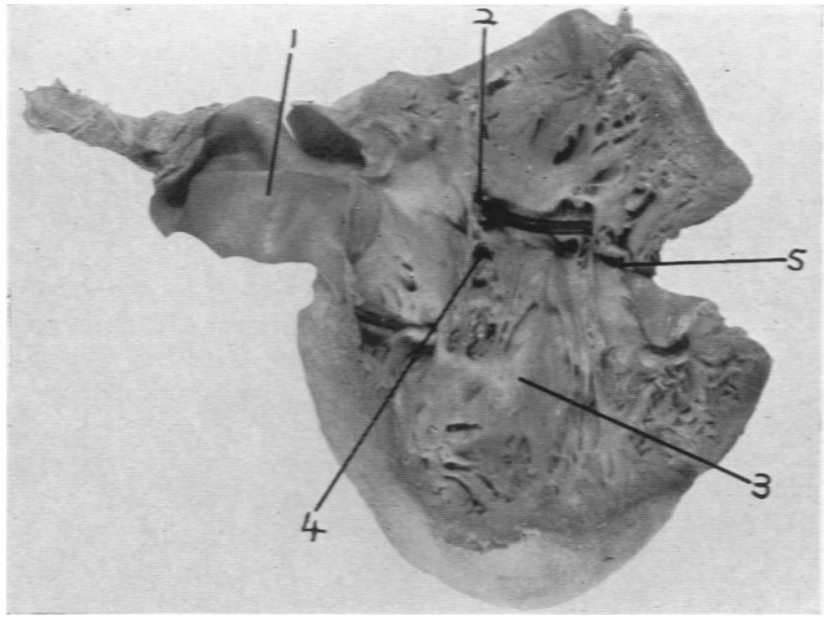

Fig. 2-Anterior view of the heart.

1 =aorta; 2 =pulmonary orifice; 3 = ridge representing interventricular septum; $4=$ right auriculo-ventricular orifice; $5=$ left auriculo-ventricular orifice.



FiG. 3.-Posterior view of the heart with auricke opened.

$1=$ left pulmonary veins; 2 =right pulmonary veins; 3 =superior vena cava; $4=$ inferior vena cava; $5=$ right auriculo-ventricular orifice; 6 =lert auriculo-ventricular orifice; $7=$ right auricular appendage; 8 =left auricular appendage; 9 =rudimentary interauricular septum; 10 =mycotic aneurysm of pulmonary artery)

Fig. 4.-Superior view of the heart.

$1=$ Pulmonary artery with wire through pulmonary valve; $2=$ rupture in mycotic aneurysm; $3=$ right pulmonary veins; $4=$ superior vena cava; 5 =right auricular appendage; $6=\mathrm{left}$ auricular appendage.
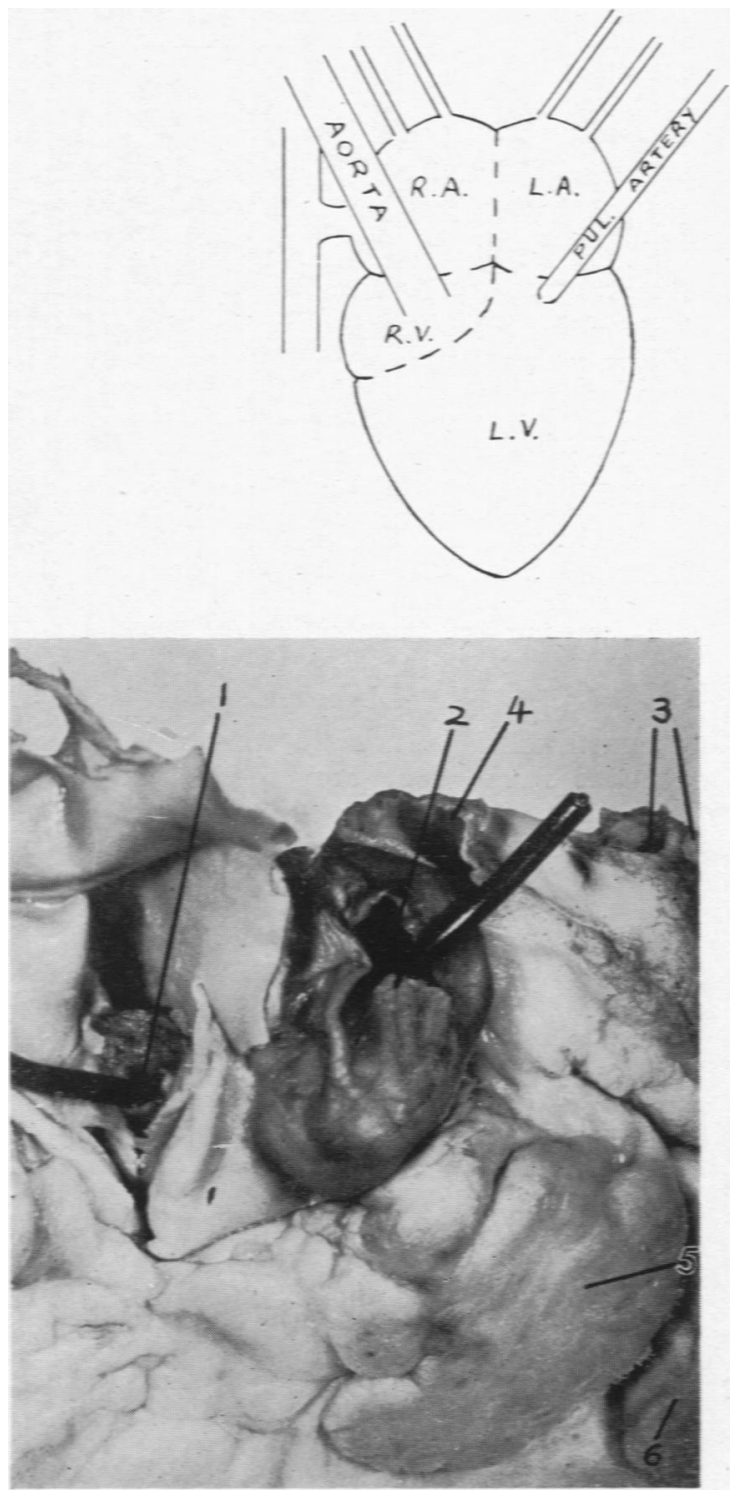
The formol gel reaction was negative.

The serum alkaline phosphatase level was $10 \mathrm{King}-$ Armstrong units.

A radiograph of the chest showed a confluent, mottled area of opacities at the right base with an area of infiltration in the right mid-zone.

Penicillin, 200,000 units 4-hourly, was begun, but petechiae continued to appear for some days and mild pyrexia up to $100^{=}$started on February 28 . The face became slightly oedematous. However, the child's general condition seemed better and she took her food well. On March 4 she sat up in bed suddenly, collapsed, and was dead in about a minute.

Necropsy Findings. The relevant findings were confined to the cardiovascular system. On opening the pericardium the sac was found to be full of blood which had escaped from a ruptured mycotic aneurysm the size of a kidney bean on the pulmonary artery just proximal to its bifurcation. The artificial ductus was found to be patent and not diseased. The heart was considerably enlarged and consisted mainly of an hypertrophied and dilated left ventricle. The abnormalities found were as follows: (1) transposition of the great vessels with a right aortic arch: (2) gross enlargement of the left ventricle: (3) a diminutive right ventricle: (4) virtual absence of the inter-ventricular septum which was represented by a narrow fold: (5) valvular pulmonary stenosis: (6) both auricles small and separated only by a rudimentary fold similar to that between the two ventricles; (7) two of the pulmonary veins drained into the right auricle and two into the left: (8) the superior and inferior venae cavae entered the right auricle as a common vessel; (9) a mass of vegetations was present on the right auriculoventricular valve and on the stenosed pulmonary valve. The auriculo-ventricular valves appeared normal and the coronary arteries were normally placed. Thus the heart was functionally bilocular.

\section{Discussion}

Functionally, this child possessed a single ventricle from which both great vessels sprang. In such a patient it is of importance to know whether the pulmonary artery is stenosed or not, for in the latter case the pressure in this vessel will be as great or greater than that in the aorta with the result that a pulmonary-systemic anastomosis will be of no benefit, while in the former the pulmonary blood supply will be increased by such an operation and the patient will benefit. In this instance the absence of the pulmonary cone and clear lung fields favoured a pulmonary stenosis, although the other abnormalities were not diagnosed, and the operation caused considerable improvement.

Hurst, Gleason and Schemm in 1949 reported a case of subacute bacterial endocarditis in a girl of 10, two years after Blalock had operated upon her for the tetralogy of Fallot. This girl recovered, and they mentioned a personal communication from Taussig that she had seen such a complication in four cases up to that date, but gave no details. No other examples appear to have been recorded since then.

\section{Summary}

A case is described in which infective endocarditis caused death by rupture of a mycotic aneurysm of the pulmonary artery two and a half years after a Taussig-Blalock operation had been performed.

Post-mortem examination showed that the heart was functionally bilocular and that there was transposition of the great vessels.

We are indebted to Dr. Alan Booth, radiologist to the Royal Hospital, Wolverhampton, for help in the interpretation of the radiographs, and to Mr. D. R. Paton, of the Photographic Department of the Royal Hospital, for the photographs.

\section{REFERENCES}

Brown, J. W. (1950). 'Congenital Heart Disease,' 2nd ed. London.

Gasul, B. M., Richmond, J. B. and Krakower, C. A. (1949). J. Pediat., 35, 413.

Hurst, W. W., Gleason, A. L. and Schemm, F. R. (1949). Northw. Med., Seattle, 48, 763.

Sokolow, M. and Edgar, A. L. (1950). Amer. Heart J., 40, 232. 